\title{
Acessibilidade e desenvolvimento urbano: o caso de Campos do Jordão*
}

\author{
Juliana da Camara Abitante ${ }^{1}$ \\ Raquel Regina de Oliveira Martins Felix ${ }^{2}$ \\ Josiane Palma Lima ${ }^{3}$
}

\begin{abstract}
Resumo
O desenvolvimento urbano das cidades pós-modernas gera maiores distâncias entre os locais de habitação e as oportunidades da cidade, interferindo na acessibilidade dos indivíduos aos equipamentos urbanos. Dessa forma, este trabalho apresenta um diagnóstico da acessibilidade e do desenvolvimento urbano por meio de interpretações de registros documentais históricos e dados socioeconômicos do município de Campos do Jordão - SP. O estudo de caso contou com o auxílio do Sistema de Informação Geográfico (SIG), o qual aborda a configuração urbana e a acessibilidade por área de abrangência aos equipamentos urbanos da cidade. Dessa maneira, foi possível identificar espacialmente as localizações de maior carência de equipamentos e, assim, disponibilizar aos gestores públicos suporte para prever investimentos na área de infraestrutura urbana, sistemas de transporte e instalação de novos equipamentos. Ademais, os resultados apresentados são o diagnóstico de uma situação, os quais corroboram as decisões na área de acessibilidade urbana.
\end{abstract}

Palavras-chave: Acessibilidade. Área de abrangência. Campos do Jordão.

\begin{abstract}
The urban development of postmodern cities creates longer distances between housing sites and city's opportunities, affecting the accessibility of individuals to urban equipment. Thus, this paper presents a diagnosis of accessibility of individuals and urban development through interpretations of historical documentary records and socioeconomic data of the city Campos do Jordão, SP. The case study includes data analysis support by a geographic information system (GIS), which addresses the urban configuration and accessibility by area of coverage to the city's urban facilities. However, the results shown are the diagnosis of a situation that corroborates decisions for the accessibility in urban area. In this way, it was possible to identify spacial locations of greatest need equipment and forecast public investment in urban infrastructure area, transportation systems and the installation of new equipment.
\end{abstract}

Keyword: Accessibility. Area of coverage. Campos do Jordão.

\section{Introdução}

O desenvolvimento urbano nas cidades pós-modernas trouxe consigo uma maior ocupação do território, uma crescente necessidade de deslocamentos e maiores distâncias entre os locais de habitação e as oportunidades oferecidas pela cidade. De acordo com Arruda

\footnotetext{
${ }^{1}$ Mestre em Desenvolvimento Tecnologias e Sociedade. Professora do Departamento de Arquitetura e Urbanismo da UNITAU. jcabitante@gmail.com

${ }^{2}$ Mestre em Desenvolvimento Tecnologias e Sociedade. Consultora Ambiental.raquel_felix_unifei@yahoo.com.br

${ }^{3}$ Doutora em Engenharia de Transportes. Pesquisadora do Programa de Pós-Graduação em Engenharia de Produção e do Programa de Pós-Graduação em Desenvolvimento, Tecnologia e Sociedade da Universidade Federal de Itajubá (UNIFEI). jpalmalima@gmail.com

* Os autores agradecem ao CNPQ, à FAPEMIG e à CAPES pelo apoio financeiro concedido aos projetos que subsidiaram o desenvolvimento deste trabalho.
} 
e Lima (2013), a acessibilidade universal trata da equiparação das oportunidades de forma geral; logo, do acesso igualitário de todos às funções sociais da cidade. O Ministério das Cidades (2006), no seu documento "Brasil Acessível", reforça que a acessibilidade deve ser vista como parte de uma política de mobilidade urbana que propicia a inclusão social, a equiparação de oportunidades e o exercício da cidadania às pessoas com deficiência e idosos, promovendo o respeito aos seus direitos fundamentais.

Nesse sentido, compreender a importância da acessibilidade urbana é fundamental na busca de soluções mais eficientes para um desenvolvimento sustentável. As questões de uso do solo, localizações das habitações, configurações espaciais, oportunidades da cidade, crescimento urbano e ainda políticas públicas nacionais e locais são fatores relativos às questões de acessibilidade, sempre presentes na pauta das discussões do urbanismo contemporâneo. Dessa maneira, o trabalho apresenta um diagnóstico da acessibilidade e do desenvolvimento urbano por meio de interpretações de registros documentais históricos e de dados socioeconômicos do município de Campos do Jordão - SP. O estudo de caso contou com auxílio do Sistema de Informação Geográfico (SIG), para análise de dados, o qual aborda a configuração urbana e a acessibilidade aos equipamentos públicos e privados da cidade.

A distribuição dos equipamentos públicos bem como a localização da população são elementos para compreender a acessibilidade. No intuito de realizar uma análise interpretativa, foram delimitadas áreas de abrangência, a partir dos equipamentos urbanos, com ferramentas de análise de redes no SIG. Os raios de abrangência dos equipamentos urbanos foram definidos por meio de brainstorm.

Os conceitos de mobilidade e acessibilidade têm definições distintas, no entanto são complementares e estão relacionados. A acessibilidade possui relação direta com o indivíduo, sua necessidade de deslocamento e o esforço para alcançar suas atividades cotidianas. Já a mobilidade engloba toda infraestrutura relacionada às viagens da população no espaço urbano. Este trabalho, além de apontar o eixo conceitual dos termos acessibilidade e mobilidade, apresenta o ordenamento jurídico. Demonstra a atual configuração espacial urbana brasileira e a tendência aos subcentros, bem como sua relação com a acessibilidade.

\section{Acessibilidade - legislações e conceitos}


As discussões de mobilidade e acessibilidade, no âmbito da legislação brasileira, derivam da Constituição Federal de 1988. Em seu artigo 182, que rege sobre política urbana, é determinado que o poder público municipal tem como função elaborar o plano diretor para as cidades com mais de 20.000 habitantes. Porém, apenas em 2001, foi sancionada a Lei $n^{\circ}$ 10.257, Estatuto da Cidade, que regulamenta os artigos 182 e 183 da Constituição Federal. Em relação à Política Urbana Municipal, estabelece o Plano Diretor como instrumento básico norteador da política de desenvolvimento e expansão urbana. A Lei $n^{\circ} 12.587$, de 2012, que define as diretrizes da Política Nacional de Mobilidade Urbana, constitui mais um avanço no que tange à legislação e atribui às cidades a responsabilidade de repensar as questões de mobilidade nos municípios.

A acessibilidade apresenta-se, na maioria dos casos, vinculada aos critérios do desenho universal, orientada ao livre deslocamento das pessoas com mobilidade reduzida. No entanto, a acessibilidade aplica-se a toda sociedade e não apenas aos que possuem dificuldades de deslocamento. Essas barreiras podem ser econômicas, sociais, físicas e até mesmo culturais, sendo, assim, várias as definições de acessibilidade encontradas na literatura. Morris et al. (1978) definem acessibilidade como uma medida de separação espacial das atividades humanas. A acessibilidade definida por Geurs e Wee (2004) trata da relação entre o uso do solo e os sistemas de transportes que permitem a (grupos de) indivíduos o alcance às atividades e aos destinos através de combinações de modos de locomoção. Vasconcellos (2000) define acessibilidade como a facilidade de atingir os destinos desejados. Já para Raia (2000), acessibilidade é uma medida do esforço empreendido para se ultrapassar uma separação espacial, levando em conta as oportunidades e o sistema de transporte. Complementando, Litman (2014) define acessibilidade como a capacidade geral das pessoas para atingir aos serviços e atividades (oportunidades); incluindo, portanto, o tempo e o dinheiro que indivíduos e empresas devem aplicar ao modo de transporte.

A partir dessas definições, pode-se afirmar que a distância entre a origem do indivíduo e o seu destino ou oportunidade é componente para mensurar a acessibilidade; portanto, a ocupação do solo é considerada como posicionamento das atratividades e localização das habitações. Por meio dos conceitos discorridos, destaca-se a relação entre o uso do solo e a acessibilidade, sendo ambos mutuamente dependentes, pois, se o uso do solo da área habitacional permite que os moradores dessa região acessem as oportunidades, com pequenas distâncias, com menores deslocamentos, a acessibilidade é garantida. Sendo a 
ocupação horizontal do território um fenômeno intrínseco ao crescimento urbano, fornecer equipamentos urbanos em diferentes localizações faz-se pertinente para atender às demandas da população de determinada região. Nesse sentido, os subcentros geram menores distâncias entre as habitações e seus pontos de destino.

O crescimento das cidades e a ocupação do território pelas habitações, no período pósindustrialização, geram demandas de oportunidades em diferentes locais. Com a oferta de oportunidades próximas às habitações, é possível suprir as necessidades em um menor raio de abrangência, criando-se subcentros. Kneib (2008) demonstra que os centros possuem como característica a acessibilidade privilegiada, sendo locais de atração de pessoas, viagens, diversos tipos de atividade e construções. Essas qualidades valorizam a área até o momento em que se instaura um processo de saturação, no qual a acessibilidade é diminuída. Então, essa área entra em decadência, o que gera um novo processo de descentralização. Assim, outras áreas atrativas, providas de investimentos locais e acessibilidade, geram novas centralidades.

O Brasil, na década de 1980, apresentou um acentuado empobrecimento aliado à urbanização (Caldeira, 1997). A população de menor poder aquisitivo instalou-se no espaço urbano, em loteamentos à margem da legalidade, ora nas periferias, causando uma expansão da cidade, ora em favelas e cortiços, nas áreas centrais das cidades. Segundo Caldeira (1997), as classes média e alta são atraídas pelos enclaves fortificados, que são espaços privados, fechados e monitorados, com a finalidade de residir, consumir, trabalhar ou obter lazer. A divisão social do espaço urbano, nas cidades latino-americanas, com a reclusão de certos bairros, é destacada por Janoschka (2002), que aponta este fenômeno como uma forma de desintegração social mediante as barreiras físicas e de acessos. Para tornar a cidade igualitária a todos, os equipamentos com maior regularidade de acesso pela população são os que merecem maior atenção por parte da gestão pública.

Para melhor interpretação da distribuição espacial dos equipamentos públicos e privados na área urbana e da maneira como a localização interfere na acessibilidade, recorrese ao uso do SIG, onde se encontra suporte necessário para a análise espacial da acessibilidade. Segundo Câmara et al. (2014), o SIG possibilita traduzir o mundo real para o ambiente computacional. As representações dependem do modo como o observador percebe o espaço, de sua experiência e necessidade específica. O uso do Sistemas de Informação Geográfica no estudo da acessibilidade é largamente difundido no meio acadêmico, verificado 
nos trabalhos de Tobias et al. (2012), Raia (2000), Lima et al. (2004), Kneib (2012). A utilização de um SIG permite uma melhor interpretação do território, pois possibilita o manejo de dados e destaca as informações necessárias para a análise de acessibilidade. Aspectos como sistema viário, caracterização do meio físico (relevo e hidrografia), uso do solo e equipamentos de educação, saúde, comércio, serviços municipais e bancários serão analisados neste trabalho com o uso de um SIG.

\section{Campos do Jordão}

O município de Campos do Jordão está inserido na Região Metropolitana do Vale do Paraíba, Litoral Norte e Serra da Mantiqueira (RMVPLN), região que possui atração turística regional e nacional (EMPLASA, 2011). Possui integração territorial com fluxos de deslocamentos entre as cidades do Vale do Paraíba, Serra da Mantiqueira e sul do estado de Minas Gerais, os quais geram uma integração regional e buscam destinos como saúde, educação e emprego. De acordo com dados levantados em 2010 pela Emplasa (2011), Campos do Jordão possui taxa de urbanização de 99,4\%, com uma população de 47.789 habitantes. A área do município é de 290,05 km² (IBGE, 2010), com densidade habitacional de 164,49 hab/ $\mathrm{km}^{2}$ (habitantes por quilômetro quadrado).

Este estudo expõe uma pesquisa qualitativa do fenômeno urbano, em especial a questão da acessibilidade, com enfoque descritivo e interpretativo. Inicialmente, realizou-se uma investigação da evolução temporal do crescimento urbano, aliado à história do município por meio da pesquisa documental. O acervo documental utilizado para o estudo desse desenvolvimento contou com mapas cadastrais, fotografias aéreas, imagens de satélites. Os dados coletados são encontrados nas seguintes fontes: Secretarias de Planejamento, Meio Ambiente e Educação da Prefeitura Municipal de Campos do Jordão, Instituto Brasileiro de Geografia Estatística (IBGE), IG (Instituto Geológico) e Embrapa (Miranda, 2005). Assim, concebeu-se uma série histórica da dinâmica de ocupação e morfologia urbana contextualizada com a cronologia de fatos. Em um segundo momento, realizou-se uma análise espacial, com interpretação de dados georreferenciados por meio de mapas processados em ambiente SIG. 
3.1 Registros históricos de crescimento e desenvolvimento urbano do município

Ao final do século XIX, em razão do meio físico, Campos do Jordão atraía doentes afetados pela tuberculose em busca da cura pelo tratamento da climatoterapia. Iniciou-se, então, o ciclo de cura, e o desenvolvimento urbano ocorreu por meio de modelos higienistas (Bertolli Filho, 2001). As diretrizes urbanísticas orientavam o crescimento da cidade com baixa densidade habitacional, à ocupação territorial de forma dispersa e linear no eixo do rio, de modo que essa ocupação se tornou um aspecto de expansão determinante na setorização de classes sociais, definindo bairros para a população residente e para os turistas. Os acessos à cidade davam-se através de trilhas, ou pela estrada de ferro, concluída em 1919. Na década de 1930, foi construída a atual rodovia SP-50, que liga o município a São José dos Campos (SP).

Entretanto, na década de 1950, a cura por climatoterapia perdeu o significado científico no país (Bertolli Filho, 2001), e a cidade deixou de investir no tratamento de tuberculose. Em decorrência disso, institui-se o ciclo de turismo na cidade, com o começo da instalação da estrutura hoteleira existente e incentivada até os dias de hoje.

Na década de 1970, a cidade recebeu estudos urbanísticos como o Código de Diretrizes do Sistema Viário, Código de Usos do Solo e Proteção à Paisagem, Código de Edificações (Lei no 1097 de 1978) e Código do Parcelamento do Solo (Paulo Filho, 1986). Em 1978, o Governo do Estado de São Paulo passou o município de estância hidromineral para estância turística, o que restabeleceu a autonomia político-administrativa. Segundo Paulo Filho (1986), na década de 1980, a cidade sofreu uma alta especulação imobiliária, com a implantação indiscriminada de loteamentos, fato ocasionado pela expressão turística do município.

A primeira centralidade constituída na cidade foi a vila Jaguaribe. Atualmente, a cidade tem como principais centralidades as vilas Abernéssia, Jaguaribe e Capivari, conforme é apresentado na Figura 1, distribuídas ao logo de um eixo articulador, que funciona como um cruzamento linear e sequência de nós da malha urbana secundária.

Em 2003, foi sancionada a Lei Municipal $n^{\circ}$ 2737/03, que dispõe sobre a aprovação do Plano Diretor Estratégico de Campos do Jordão. Institui os objetivos estratégicos da administração pública, que inclui aspectos acerca da mobilidade urbana sustentável, entre eles, melhoria da fluidez do tráfego, adequação da circulação e dos estacionamentos para turistas, vias panorâmicas (Norte, Sul e Perimetral Norte) e ciclovias na área urbana, para 
serem utilizadas não apenas como esporte e lazer, mas para estimular esse meio de transporte.

Figura 1 - Bairros de Campos do Jordão com destaque para o eixo viário principal

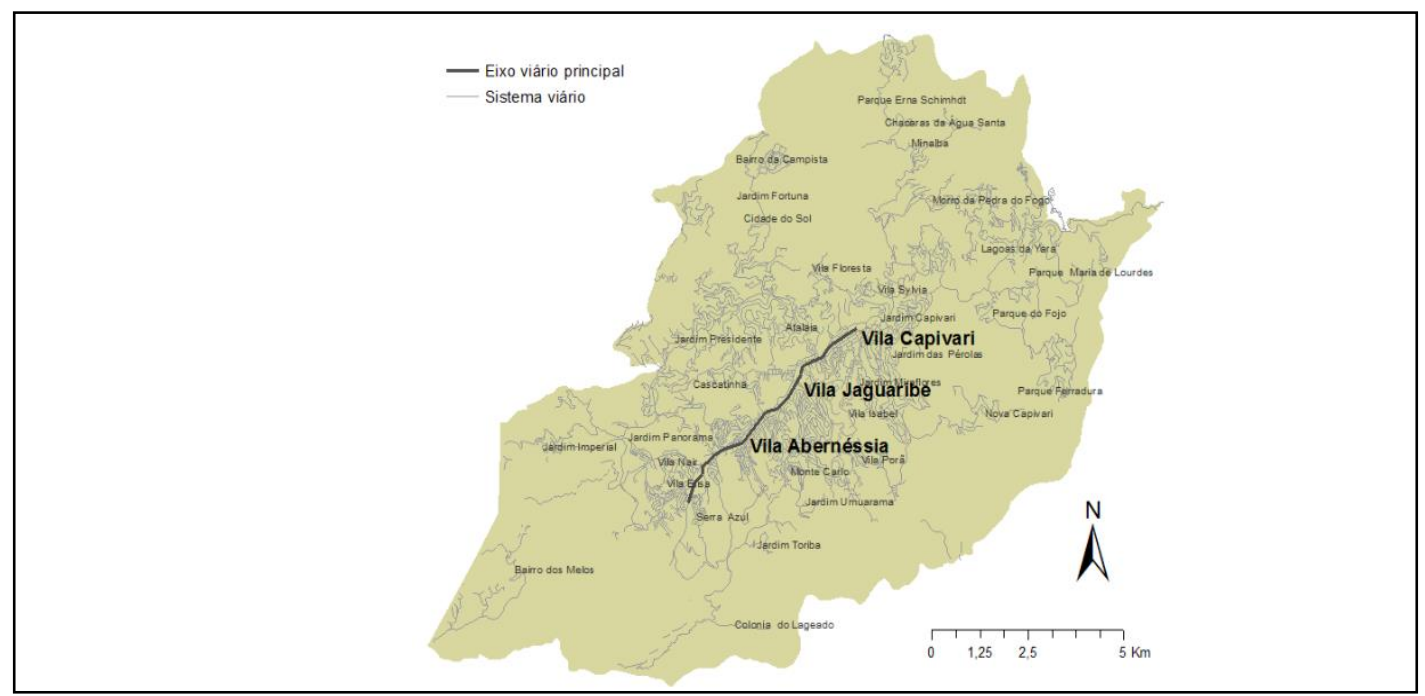

Fonte: COPASA (2010).

O Plano Diretor aborda a necessidade de uma política direcionada para repensar as questões do tráfego na cidade por meio de um Plano Municipal de Transporte, inclusive considerando os bairros periféricos. A preocupação com a mobilidade urbana existe e foi explicitada em Lei Municipal desde 2003, antes mesmo da regulamentação da Lei Federal $n^{\circ}$ 12.587. No entanto, após doze anos de concepção do Plano Diretor, como na maioria das cidades brasileiras, poucas intervenções foram efetivadas, e, com relação à acessibilidade, as estratégias são voltadas, na sua maioria, para intervenções em regiões centrais.

Em 2007, foi promulgada a Lei Municipal no 3.049/07, que dispõe sobre o zoneamento de uso e ocupação do solo, enfatizando que a vocação do município é o turismo. Portanto, verifica-se essa intencionalidade no desenvolvimento urbano na análise das diretrizes do Plano de Urbanização de Campos do Jordão, Projeto de Lei $n^{\circ} 193$, desde a primeira metade do século XX. As orientações são voltadas ao crescimento da cidade com baixa densidade habitacional para a ocupação territorial de forma dispersa e linear, para o espraiamento do tecido urbano e para a setorização.

\subsection{Características geomorfológicas do município}


O rio Sapucaí, de grande importância para região, nasce no município a 1620 metros de altitude, sendo o principal rio da Bacia Hidrográfica do Rio Sapucaí, abrangendo 51 municípios paulistas e mineiros, atendendo a um total de 770.491 habitantes (COPASA, 2010). A Figura 2 apresenta os aspectos geográficos e do meio físico do município em análise.

Figura 2 - Caracterização dos aspectos geográficos e do meio físico de Campos do Jordão

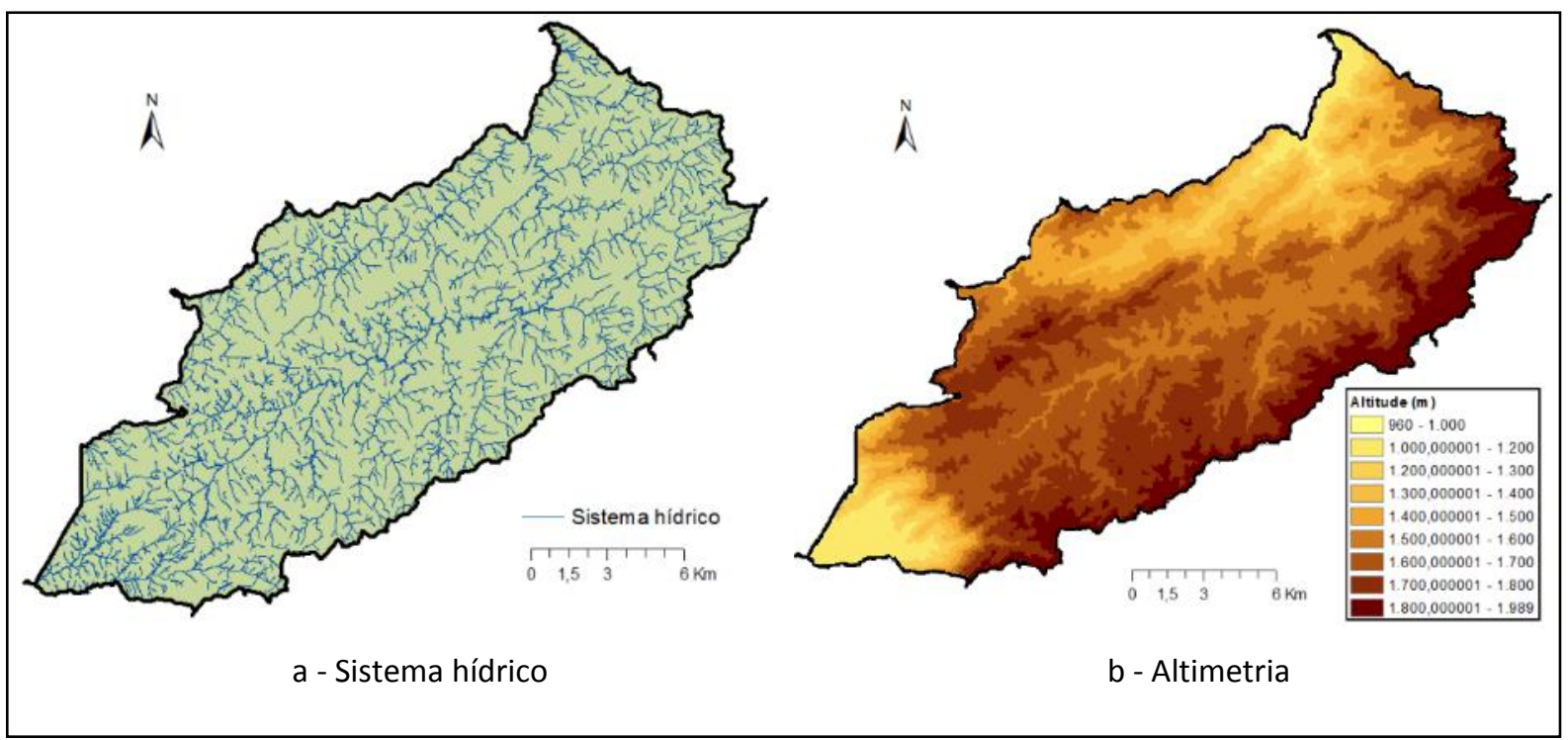

Fonte: COPASA (2010).

A Figura 2a mostra o rico sistema hídrico da cidade, e, na figura $2 b$, é possível verificar o gradiente de altitude - de mais de 1000 metros no interior do município - e o seu ponto culminante, que é de 1989 metros. Ambos aspectos foram importantes no desenvolvimento urbano e na ocupação territorial; o recurso hídrico do rio Sapucaí e seu leito de relevo ameno facilitaram a ocupação urbana, que se estende no entorno do rio, de forma linear. 
3.3 Acessibilidade - uma interpretação por meio de distribuição espacial e dados socioeconômicos

Diferentemente do final do século XIX e início do século $X X$, quando a população procurava o município para tratamentos de saúde, atualmente há uma grande quantidade de turistas que buscam o contato com a natureza e o requinte dos serviços gastronômicos e hoteleiros oferecidos na cidade. Esse fato colabora com a expansão da área urbana, onde, cada vez mais, verificam-se instalações de restaurantes, hotéis e residências para atender aos turistas. Além do turismo que busca o frio da montanha, do conforto urbano de restaurantes, do comércio e da hotelaria sofisticada, Campos do Jordão também se diversificou em outros segmentos: (i) o turismo ecológico e campestre, com atrações de reservas florestais, hípicas e atividades out door; (ii) o turismo de negócio, com diversas opções de salas de convenções, na estrutura hoteleira, onde são realizados congressos e feiras na cidade; e o (iii) turismo cultural, atraído pelo Festival de Inverno, importante evento nacional de música clássica.

No decorrer do crescimento do traçado urbano - e para atender a uma demanda imobiliária - foram criados loteamentos de alto padrão nas áreas periféricas, alguns próximos a reservas florestais, principalmente para atender à oferta turística. Para o turista, a cidade tem um significado bucólico, a sensação de estar no campo; por outro lado, os moradores fixos dessas residências estão isolados e distantes dos equipamentos e serviços oferecidos pela cidade. Os loteamentos turísticos possuem características residenciais monofuncionais, ou seja, não oferecem serviços, nem tanto pelo impedimento do funcionamento de comércio pela regulamentação do uso do solo, mas, sobretudo, pela falta de adensamento humano, necessário para o consumo. Além da dispersão geográfica, ainda estão, na maior parte dos dias, desocupados, pois são casas de veraneio.

Em termos de infraestrutura urbana, áreas mais afastadas do centro tiveram que ser providas de rede viária (figura $3 b$ ) e de sistema de transporte público, deslocando os recursos disponíveis para o suprimento das necessidades específicas dessa região. A manutenção dessas vias, mesmo que pouco utilizadas, geram uma demanda orçamentária constante ao poder público. A situação dos loteamentos dispersos contribuiu para uma grande quantidade de vazios urbanos, decorrentes da escolha de melhores terrenos pelo aspecto geomorfológico (terrenos menos acidentados). 
A Figura 3 apresenta a auto-segregação e evolução da mancha urbana em Campos do Jordão, elaborada para identificar as extensões territoriais que restringem a circulação pública.

Figura 3 - Auto-segregação e evolução da mancha urbana Campos do Jordão

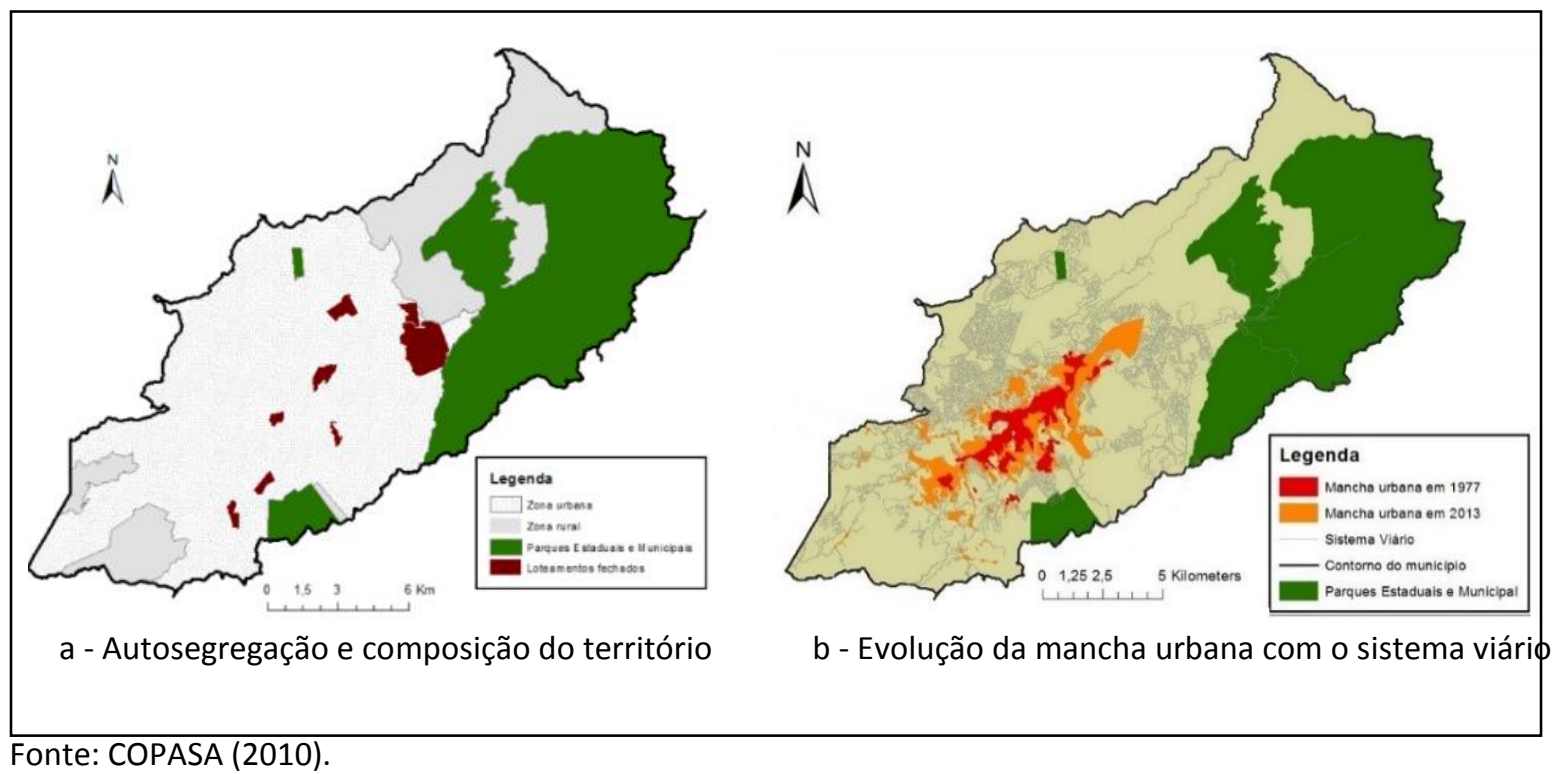

A partir do mapa de divisão de lotes da Prefeitura Municipal de Campos do Jordão, criou-se no SIG polígonos, delimitando as áreas, em torno de condomínios e loteamentos fechados de maior porte. A partir da figura $3 a$, identificamos as zonas urbanas, as rurais e as áreas de reserva.

A Figura 4 apresenta a densidade demográfica e a distribuição de renda no município. A figura 4a apresenta a densidade demográfica por setor censitário, elaborada com base em informações do Censo Demográfico de 2010 (IBGE, 2010). Dessa forma, identificou-se a densidade demográfica por setor censitário, considerando o número de habitantes por quilômetro quadrado e a classificação em nove classes. Observa-se que a área urbana do município não possui densidade habitacional homogênea em todo o território; a população, concentrada, reside em torno do eixo principal da cidade, existindo áreas com um sistema viário extenso e de forma espraiada.

A figura $4 \mathrm{~b}$ apresenta a distribuição de renda por setor censitário. Nota-se que o valor de renda mensal máximo é de quatro salários mínimos por setor censitário. Apenas dois setores possuem médias de três a quatro salários mínimos, com predomínio de um a dois salários mínimos por setor censitário. Ou seja, a cidade possui uma média baixa de rendimento mensal, 
e aqueles que possuem um rendimento maior não estão alocados de forma concentrada, de modo a aumentar a média por setor. Observa-se que a população residente de maior renda está alocada no centro, e, independentemente da renda, a de maior densidade habitacional possui acessibilidade através da localização central da residência. Constata-se que a periferia de Campos do Jordão não é necessariamente a localização da população de baixa renda.

É importante destacar que os dados não permitem identificar as residências de turistas, pois sua coleta é feita pelos habitantes locais. Vários setores censitários que possuem baixas rendas são bairros de classes sociais elevadas (bairros de turista), porém os proprietários não residem no local, de modo que os dados do IBGE não conseguem demonstrar essa realidade, uma vez que trabalha apenas com a população residente.

\section{Figura 4 - Densidade demográfica e renda}

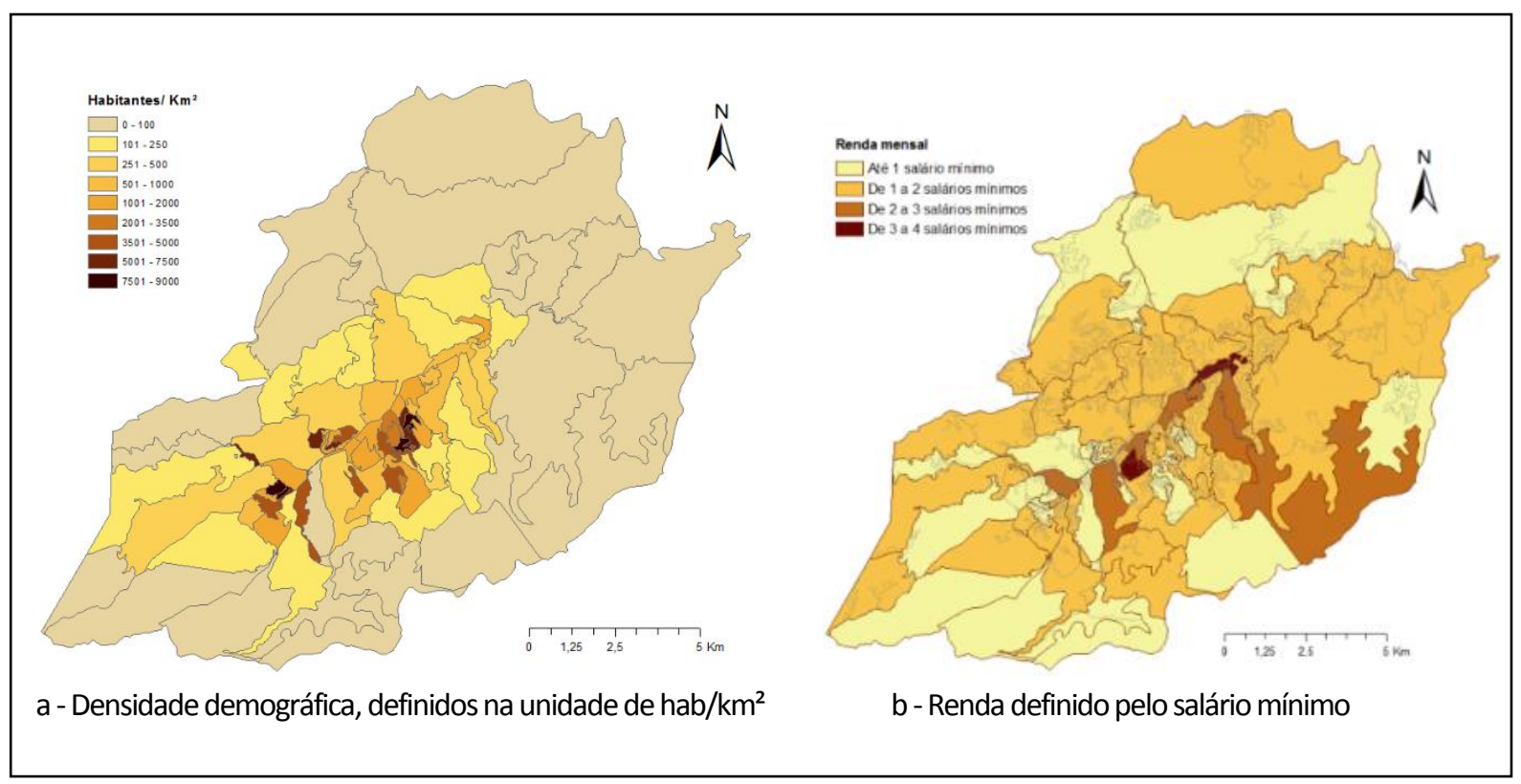

Fonte: COPASA (2010).

Para definir a acessibilidade em virtude da distância dos equipamentos urbanos à habitação, foi realizada a análise de abrangência do serviço sobre a rede viária. Utilizou-se a análise de rede, por meio do SIG ArcGis 10.1 da Esri com a ferramenta "New Service Area". Foram selecionados e georreferenciados os equipamentos públicos e privados com maior destaque e importância quanto à utilização nas atividades diárias e contribuição de sua localização para a melhoria da qualidade de vida da população. Assim, selecionaram-se os 
equipamentos de saúde, educação (infantil e médio); serviços municipais, bancários e de comércio localizados na cidade.

As classes de declividade, de acordo com a Embrapa (2006), conforme Quadro 1, foram utilizadas como base de dados nas figuras 5, 6 e 7. A partir desta classificação, verifica-se que o território urbano de Campos do Jordão possui sua topografia com declividade predominante entre $8 \%$ e $45 \%$, ou seja, prevalecem as taxas de classificação entre ondulado e fortemente ondulado, e não possui a primeira classe de declividade. A declividade do relevo e, consequentemente, das vias é um fator que interfere nos deslocamentos, tanto para pedestres, ciclistas e veículos automotores. Quanto maior a inclinação da via, maior é o esforço de deslocamento.

\section{Quadro 1 - Classe de declividade}

\begin{tabular}{|l|r|}
\hline Classes de declividade & Relevo \\
\hline $0-3 \%$ & Plano \\
\hline $3-8 \%$ & Suave ondulado \\
\hline $8-20 \%$ & Ondulado \\
\hline $20-45 \%$ & Forte ondulado \\
\hline $45-75 \%$ & Montanhoso \\
\hline$>75 \%$ & Escarpado \\
\hline
\end{tabular}

Fonte: Embrapa (2006).

Para a definição do ideal para as distâncias máximas, quanto à localização dos equipamentos urbanos em relação à habitação, para que ele seja acessível, realizou-se uma reunião com um grupo com técnicos especialistas em mobilidade urbana (pós-graduandos da UNIFEI e professores). Utilizou-se a técnica do brainstorm, que visa solucionar problemas em grupo, na qual os integrantes debatem as alternativas com o intuito de tomar uma decisão (JONES e GEORGE, 2012). Estes valores, apresentados no Quadro 2, foram definidos a partir de uma média entre as opiniões dos especialistas, desconsiderando os valores máximos ou mínimos que apresentavam discrepância do conjunto. 


\section{Quadro 2 - Distâncias máximas dos equipamentos urbanos}

\begin{tabular}{|lr|}
\hline EQUIPAMENTOS & Dist. Máx (metros) \\
\hline Educação infantil & 960,00 \\
\hline Ensino médio & 1400,00 \\
\hline Posto de saúde & 1600,00 \\
\hline Hospital & 7500,00 \\
\hline Serviços municipais & 5000,00 \\
\hline Banco & 4300,00 \\
\hline Comércio & 1660,00 \\
\hline
\end{tabular}

Fonte: Dados de pesquisa (2018).

A partir do ponto do equipamento, foram geradas linhas com o traçado sob a rede viária, com a distância definida para cada equipamento. A Figura 5 apresenta a área de abrangência dos equipamentos de educação. Os dados da localização das escolas foram obtidos na Secretaria Municipal de Educação, que forneceu informações sobre as escolas de educação infantil e as do ensino médio. A distância da área de abrangência para educação infantil é a menor entre os equipamentos; a justificativa dada no brainstorm é por se tratar de crianças menores (de 0 a 5 anos), que carecem de acompanhamento até o local.

Já a distância para escolas do ensino médio é maior, quando comparada ao ensino infantil, pois são crianças maiores e adolescentes que possuem maior autonomia e liberdade de deslocamento. A Figura $5 b$ apresenta a área de abrangência dos equipamentos de ensino médio. Os locais com maiores densidades demográficas estão atendidos pelas escolas públicas municipais. As áreas mais distantes do centro não estão cobertas de uma forma homogênea, desse modo, o aluno necessita recorrer ao transporte público para ter acesso à escola. 
Figura 5- Área de abrangência de equipamentos de educação e localização

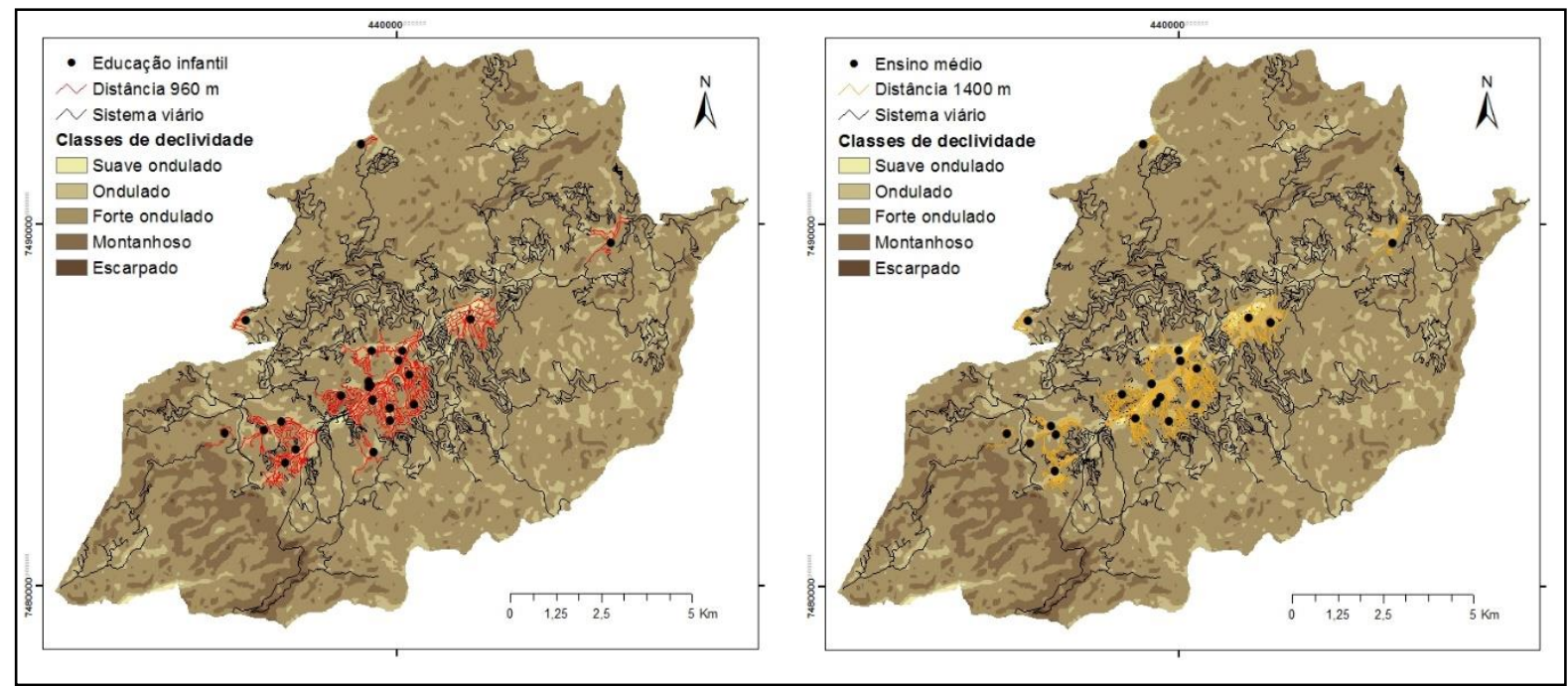

Fonte: COPASA (2010).

A prefeitura oferece auxílio de transporte ao estudante, por meio do passe escolar, a todos os alunos da rede pública do ensino fundamental, médio e particular, com desconto de $50 \%$ da passagem. Alguns alunos recebem a quantia integral, dependendo da distância entre a residência e a escola. Segundo o IBGE (2010), o município possui 46\% da população entre 18 e 24 anos, com, pelo menos, o ensino médio completo. Esta taxa está bem abaixo da média do estado, que é de 57,89\%. A taxa de analfabetismo é de 4,42 \% na cidade, ligeiramente mais alta do que a do Estado de São Paulo, que é de 4,33\% (IBGE, 2010). Nesse sentido, é válido questionar se a baixa escolaridade tem relação com a acessibilidade às escolas no município.

A Figura 6 apresenta a área de abrangência dos equipamentos de saúde. A lista dos estabelecimentos de saúde foi coletada do CNESNet, Secretaria de Atenção à Saúde, do Ministério da Saúde do Governo Federal. A área de abrangência dos postos de saúde foi definida em 1600 metros, distância máxima definida em brainstorm, e justificada em função de serem locais usualmente frequentados por moradores cadastrados nas regiões próximas onde residem. Esses moradores utilizam com maior continuidade os postos de saúde, por se destinarem exclusivamente para consultas de caráter de prevenção. O resultado da análise é apresentado na Figura 6a. Entretanto, nos hospitais de pronto atendimento, são recebidos os casos mais graves e/ou urgências, emergências, justificando uma abrangência maior de atendimento (a distância máxima definida foi de 7500 metros), principalmente por se tratarem de casos cujos deslocamentos são realizados por meio de ambulâncias ou outros tipos de veículos motorizados (Figura 6b). 
Figura 6 - Área de abrangência dos equipamentos de saúde e localização

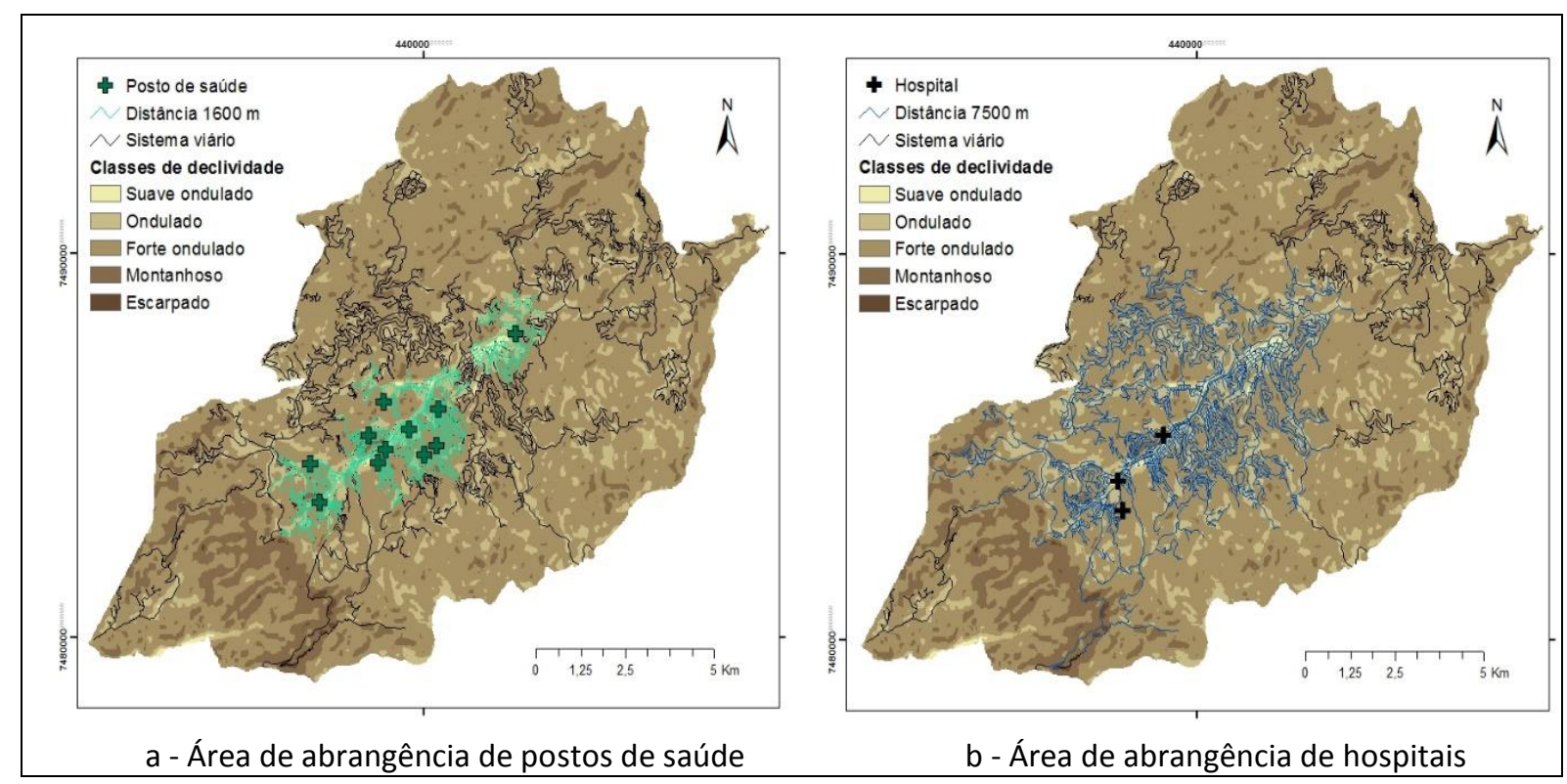

Fonte: COPASA (2010).

Verifica-se que as áreas centrais com maior adensamento populacional são assistidas pelos equipamentos de saúde, porém, nos locais mais distantes desses centros, identifica-se uma carência no atendimento. Assim, o paciente necessita percorrer grandes distâncias para ter acesso às unidades de saúde, tanto para emergências quanto para prevenção. Entretanto, existe no município o transporte realizado por ambulâncias até o hospital de pronto atendimento.

Nos equipamentos serviços bancários, foram considerados os caixas eletrônicos, as agências bancárias, as lotéricas e agência dos correios, identificados com inspeção in-loco e com auxílio do Google Maps. Quanto aos serviços municipais, foram localizadas e georreferenciadas as secretarias municipais, o gabinete do prefeito e as delegacias; os endereços foram coletados no site da Prefeitura Municipal de Campos do Jordão. A Figura 7 apresenta a categoria dos serviços e bens do município e sua área de abrangência. 
Figura 7- Área de abrangência dos equipamentos de serviços e bens e localização

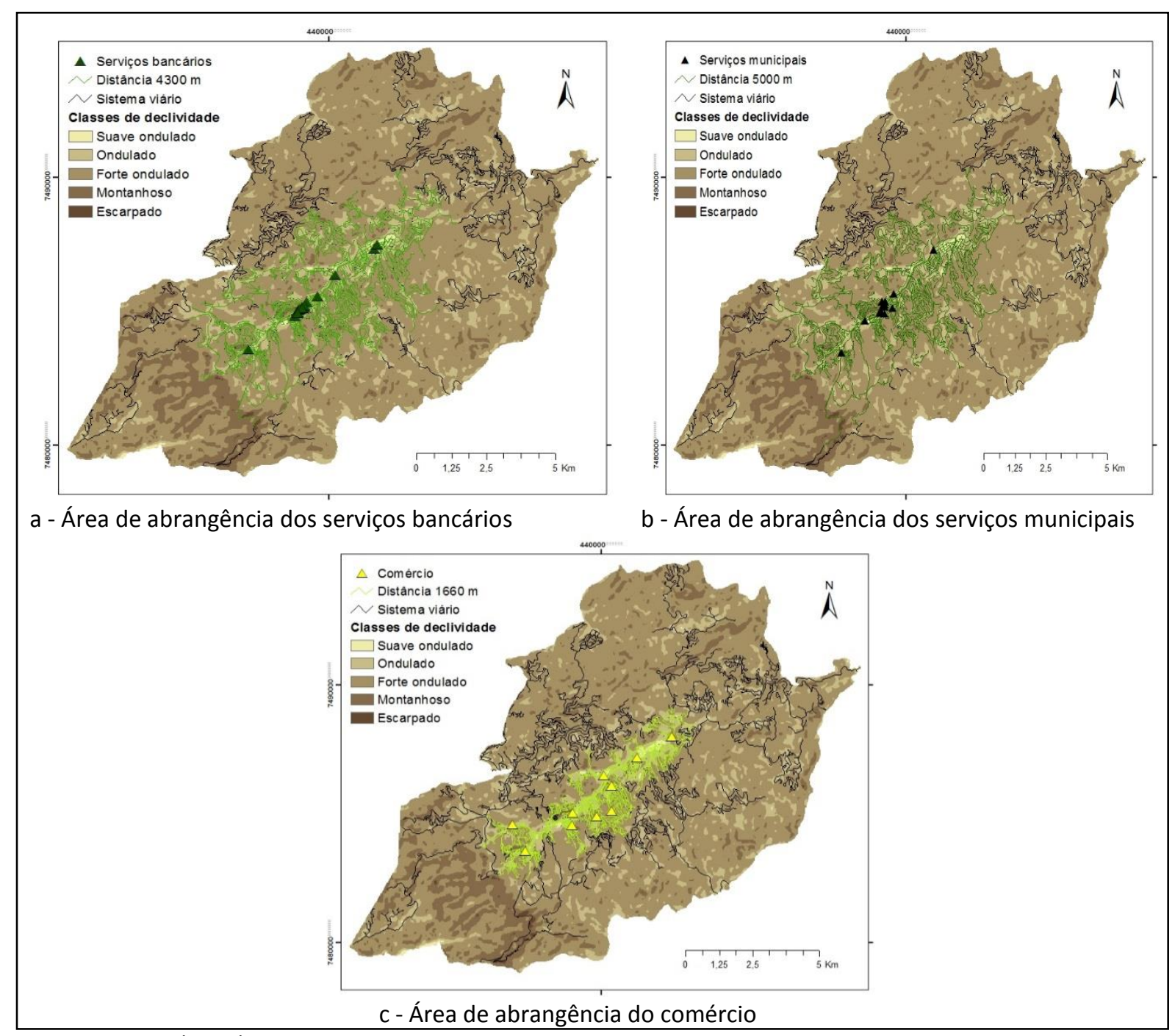

Fonte: COPASA (2010).

Os principais locais de comércio da cidade estão concentrados nas avenidas Dr. Januário Miráglia e Frei Orestes Girardi. No intuito de identificá-los, geraram-se três pontos ao longo da avenida, representando as vilas Abernéssia, Jaguaribe e Capivari. As outras áreas comerciais, em diferentes locais da cidade, foram pontuadas a partir da Lei $n=3.049 / 07$, que dispõe sobre o zoneamento de uso e ocupação do solo do município, a qual estabelece três zonas comerciais principais (PREFEITURA MUNICIPAL DE CAMPOS DO JORDÃO, 2007):

- ZC1- zona de uso predominantemente de comércio e serviço de alta densidade;

- ZC2- zona de uso predominantemente de comércio e serviço de média densidade;

- ZC3- zona de uso predominantemente residencial de baixa densidade. 
Assim, delimitaram-se mais sete pontos de comércio representando os subcentros. A zona comercial ZC1 compõe predominantemente o eixo das avenidas, já considerados anteriormente, referentes às três vilas principais. As zonas comerciais ZC2 e ZC3 atendem às zonas residenciais com comércios de pequeno porte, como exemplo mercadinhos, mercearias e farmácias. Foram consideradas as vilas Cláudia, Ferraz, Paulista, Sodipe, Guarani, Recanto Feliz e Santa Cruz. A Lei no 3.049/07 não restringe o comércio em outras zonas de uso misto residencial, ou seja, o comércio é permitido em outros locais. No entanto não foram pontuadas, pois não possuem um conjunto de estabelecimentos comerciais para serem consideradas subcentros. Destaca-se que o deslocamento é feito sobre uma base territorial com classes de declividade predominantemente ondulado e forte ondulado. Outro obstáculo à rapidez no auxílio dessas áreas mais distantes é o tipo de via, com a diminuição da velocidade nas vias não pavimentadas, afetando a qualidade do serviço.

A alta declividade e a ausência de vias na área sudoeste do mapa demonstram regiões não acessíveis, nem tampouco adequadas à ocupação urbana, já que se trata de uma região com baixa densidade populacional e desprovida de infraestrutura urbana. Com a análise das figuras 5, 6 e 7, verifica-se que os equipamentos urbanos estão concentrados em torno do eixo principal da cidade. Ademais, o município possui urbanização dispersa e horizontalizada em torno do eixo viário principal, não dispõe de continuidade de ocupação, e esses vazios urbanos são intercalados. Dessa forma, identifica-se que as extremidades dos limites municipais são locais com carência de equipamentos urbanos. De modo geral, os deslocamentos são facilitados com a utilização das vias, asfaltadas ou não, sobretudo os locais com baixa classe de declividade.

O modelo possibilitou a comparação de acessibilidade entre os diferentes equipamentos. Além disso, comparando o resultado da aplicação do método com a observação in-loco, é possível verificar a coerência em relação aos aspectos históricos da evolução urbana e do meio físico que determinaram as localizações dos subcentros e o crescimento linear em torno do eixo viário principal. Nesse sentido, pode-se afirmar que as localizações dos equipamentos urbanos não estão acessíveis a todo o território municipal. 


\section{Considerações finais}

O eixo principal da cidade, composto pelas avenidas Januário Miráglia e Frei Orestes Girardi, além de ser o articulador dos fluxos de mobilidade para o município, é também o local de referência de concentração dos equipamentos públicos, portanto toda a população tem necessidade de acessar essa região. A densidade demográfica é maior ao logo dessa linha, mas não contempla a extensão de moradia de toda a população, uma vez que a população habita todo o território da cidade de modo espraiado. O fato de a maioria dos habitantes da cidade localizarem-se em torno do centro facilita o acesso aos seus destinos cotidianos. No entanto, a localização dos habitantes em regiões mais afastadas não lhes permite facilidades de acesso, pois o uso do solo diversificado é extremamente concentrado na área central. Além disso, as áreas periféricas estão em regiões com maiores declividades e com vias não pavimentadas, o que dificulta a acessibilidade dos usuários, reduzindo-lhes a mobilidade.

A utilização do SIG foi determinante na geração das figuras, o que possibilitou a análise espacial de cobertura de abrangência, com a visualização de dados tais como localização de equipamentos, sistema viário e classes de declividade. Com a geração dos cenários de área de abrangência, verifica-se a eficiência da utilização do SIG.

A análise espacial por meio de áreas de abrangência, considerando a distância como parâmetro de acessibilidade, associada a classes de declividade, mostra-se importante para uma primeira avaliação, desde que se entendam as suas limitações. A sua importância para a análise de acessibilidade é a compreensão do alcance da área de abrangência através das vias, o que é factível com a realidade, uma vez que os deslocamentos são feitos pela rede viária. Outros fatores também são pertinentes para um cenário mais completo, como considerar o tipo de pavimento e o sistema público de transporte. Entretanto, os resultados apresentados são o diagnóstico de uma situação que corrobora decisões na área de acessibilidade urbana. Dessa maneira, foi possível identificar espacialmente os locais de maior carência de equipamentos e prever investimentos públicos na área de infraestrutura urbana, sistemas de transporte e instalação de novos equipamentos. 


\section{Referências}

Arruda, F. N.; V. F. Lima. A Política Nacional de Mobilidade Urbana e a prática da Acessibilidade. Anais do XIX Congresso Brasileiro de Transporte Trânsito. ANTP, Brasília - DF. 2013.

BRASIL. Constituição da República Federativa do Brasil, de 05 de outubro de 1988.

Lei $n$ o 10.257, de 10 de julho de 2001. Regulamenta os arts. 182 e 183 da

Constituição Federal, estabelece diretrizes gerais da política urbana e dá outras providências. Diário Oficial da União - Poder Executivo, Brasília, DF, 11 jul. 2001. Seção 1, Eletrônico, p. 1.

Lei no 12.587, de 03 de janeiro de 2012. Institui as diretrizes da Política Nacional de Mobilidade Urbana. Diário Oficial da União -Poder Executivo, Brasília, DF, 04 jan. 2012. Seção 1, p. 1.

Lei $\mathrm{N}^{\circ}$ 3049, de 02 de maio de 2007.

BERTOLLI FILHO, C. História social da tuberculose e do tuberculoso: 1900-1950 [online]. Rio de Janeiro: FIOCRUZ, 2001, 248 p. Antropologia \& Saúde collection. ISBN 85-7541-006-7.

CALDEIRA, T. P. R. Enclaves fortificados: a nova segregação urbana. Novos Estudos, CEBRAP. n. 47. p. 155-177.

CÂMARA, G. D. C.; A. M. V. MONTEIRO. Introdução à ciência da geoinformação. São José dos Campos, SP: INPE - Instituto Nacional de Pesquisa Espaciais, 2001.

CAMPOS DO JORDÃO. Lei N 2737, de 02 de maio de 2003.

COPASA. Plano Diretor de Recursos Hídricos da Bacia Hidrográfica do Rio Sapucaí. Resumo Executivo. Vida Meio Ambiente. Belo Horizonte - MG, 2010.

EMBRAPA. Centro de Pesquisas de Solos (Rio de Janeiro). Sistema brasileiro de classificação de solos. 2. ed. Brasília: Embrapa Produção de Informação; Rio de Janeiro: Embrapa Solos, 2006.

EMPLASA. Região Metropolitana do Vale do Paraíba e Litoral Norte. Estudo técnico, 2011.

GEURS, K. T.; B. V. WEE. Accessibility evaluation of land-use and transport strategies: review and research directions. Journal of Transport Geography. v. 12. p. 127-140, 2004.

IBGE. Cidades. Disponível em: http://cod.ibge.gov.br/2AJ. 2010. Acesso em: 30 dez. 2013.

INSTITUTO GEOLÓGICO. Mapeamentos de riscos associados a escorregamentos, inundações, erosão e solapamento de margens e drenagens - Município de Campos do Jordão. Relatório técnico. Eduardo de Andrade (Coordenação). v. 3. São Paulo-SP. IG/SMA, 2014. 
JANOSCHKA, M. El nuevo modelo de la ciudad latino-americana: fragmentacion y privatizacion. Santiago: EURE, 2002, v. 28, n. 85, p. 11-20.

JONES, Gareth R.; GEORGE, Jennifer M. Fundamentos da Administração Contemporânea. 4. ed. São Paulo: Bookman, 2012.

KNEIB, E. C. As diferentes escalas de análise espacial de um índice de acessibilidade. Anais do Congresso PLURIS - V Congresso Luso-brasileiro para o Planejamento Urbano, Regional, Integrado e Sustentável. Brasília: UnB, 2012.

LIMA, J. P., RODRIGUES, D. S., MENDES, J. F. G., RAMOS, R. A. R. Uma Abordagem Multicritério para avaliação da Acessibilidade. Workshop realizado dentro do acordo de Cooperação Científica Luso-Brasileira GRICES - CAPES - Universidade do Minho, 2004.

LITMAN, T. Active transportation policy issues. Canadá: Victoria Transport Policy Institute. Disponível em: http:www.vtpi.org. Acesso em: 15 nov. 2013.

MINISTÉRIO DA SAÚDE. CNESNet. Disponível em: http://cnes.datasus.gov.br/Lista_Es_Nome_Por_Estado_Municipio.asp?VEstado=35\&VMun= 350970. Acesso em: 12 set. 2014.

MINISTÉRIO DO TRABALHO E EMPREGO. Emprego e renda. Salário mínimo. Disponível em: http://portal.mte.gov.br/sal_min/. Acesso em: 17 mar. 2015.

MIRANDA, E. E. (coord.). Brasil em Relevo. Campinas: Embrapa Monitoramento por Satélite, 2005. Disponível em: http://www.relevobr.cnpm.embrapa.br. Acesso em: 19 fev. 2015.

MORRIS, J. M.; DUMBLE, P. L.; WIGAN, M. R. Accessibility indicators for transport planning. Transportation Research, Part A, v. 13, n. 2, p. 91-109, 1978.

PAULO FILHO, P. História de Campos do Jordão. Aparecida: Santuário, 1986.

RAIA, JR.; A. Azevedo. Acessibilidade e mobilidade na estimativa de um índice de potencial de viagens utilizando redes neurais artificiais e sistemas de informações geográficas. 2000. 196 f. Tese (Doutorado - Escola de Engenharia de São Carlos) - Universidade de São Paulo, São Carlos, 2000.

TOBIAS, M. S. G. Avaliação em Ambiente SIG da Acessibilidade Global Regional na Amazónia: aplicação no Baixo Amazonas - Brasil. Anais do Congresso PLURIS - V Congresso Lusobrasileiro para o Planejamento Urbano, Regional, Integrado e Sustentável. Brasília: UnB, 2012.

VASCONCELLOS, E. A. Transporte urbano nos países em desenvolvimento: reflexões e propostas. 3. ed. São Paulo: Annablume, 2000. 